\title{
Brief Communication:
}

The influx of Yaba continues to ravage the Bangladeshi population- a short summary

Jamal $M^{1}$, Ito $A^{2}$, Tanaka $N^{3}$, Tatakura $A^{4}$, Ameno $K^{5}$, Kinoshita $H^{6}$

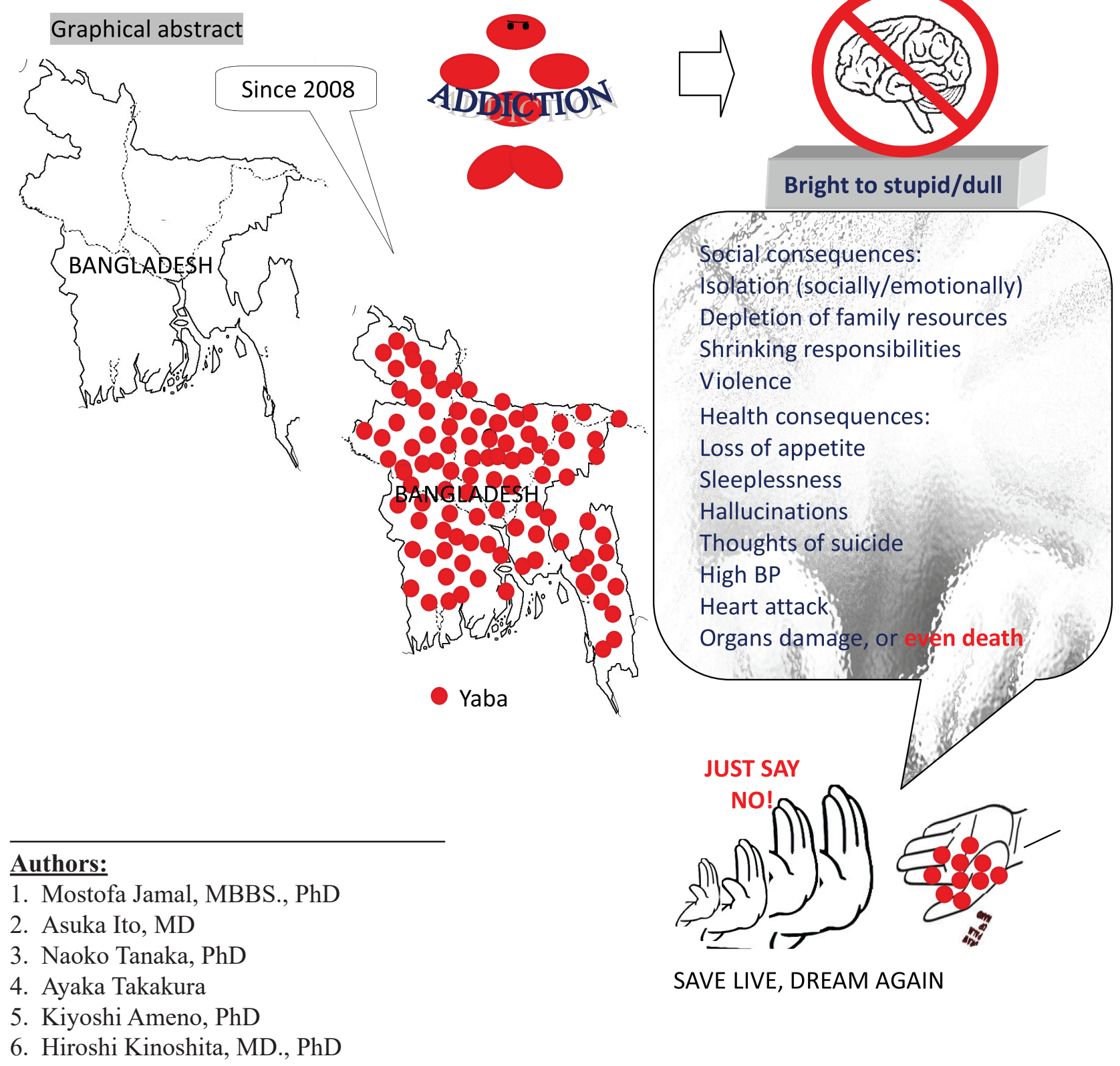

\section{Reference:}

Jamal M, Ameno K, Tanaka N, Ito A, Takakura A, Kinoshita H. Yaba addiction in Bangladesh- A crisis corroding our future, Bangladesh J Med Sci, 2016; 15(4): 503-504.

Correspondence to: Mostofa Jamal, Assistant Professor, Department of Forensic Medicine, Faculty of Medicine of Kagawa University, Japan. E-mail: jamal@med.kagawa-u.ac.jp 